\title{
PENGARUH KOMITMEN PROFESIONAL, LOCUS OF CONTROL, DAN SOSIALISASI ANTISIPATIF MAHASISWA TERHADAP WHISTLEBLOWING
} (Studi Empiris pada Mahasiswa S1 Akuntansi di Universitas Negeri Padang)

\author{
Winda Devila Zalmi ${ }^{1}$, Efrizal Syofyan ${ }^{2}$, Mayar Afriyenti ${ }^{3}$ \\ 1)Alumni Jurusan Akuntansi Fakultas Ekonomi Universitas Negeri Padang \\ ${ }^{2,3)}$ Jurusan Fakultas Ekonomi Universitas Negeri Padang \\ *Korespondensi: windadefilla@gmail.com
}

\begin{abstract}
This study aims to analyze empirically the effect of professional commitment, locus of control and anticipatory socialization of accounting students on whistleblowing. The type of this research is quantitative research, the population in this study were students of the 2014 and 2015 primary years at the Padang State University. The sample was chosen as many as 100 respondents, the data used in this study were primary data derived from questionnaires distributed to respondents. This study uses multiple regression analysis using SPSS 21 software.The results of this study indicate that professional commitment variables have a significant positive effetc on whistleblowing, internal locus of control variables have a significant positive effect on whistleblowing, external locus of control variables have a significant negative effect on whistleblowing and anticipatory socialization variable of accounting students has no significant effect on whistleblowing. The fourth hypothesis is rejected.
\end{abstract}

Keywords: Professional commitment; Internal Locus Of Control; External Locus Of Control; Anticipatory Socialization Accounting Students; Whistleblowing

How to cite (APA $6^{\text {th }}$ style)

Zalmi, W.I, Sofyan, Efrizal \& Afriyanti, Mayar. (2019). Pengaruh Komitmen Profesional, Locus Of Control dan Sosialisasi Antisipasif Mahasiswa Terhadap Whistleblowing (Studi Empiris pada Mahasiswa S1 Akuntansi di Universitas Negeri Padang. Jurnal Eksplorasi Akuntansi, 1(1) Seri C, 290-305.

\section{PENDAHULUAN}

Akuntan merupakan profesi yang salah satu tugasnya melakukan pemeriksaan atas laporan keuangan sebuah entitas dan memberikan opini terhadap saldo akun dalam laporan keuangan apakah telah disajikan secara wajar sesuai dengan standar laporan keuangan yang telah diterapkan secara konsisten. Citra akuntan yang profesional dan berperilaku etis saat ini masih 
menimbulkan keraguan, kepercayaan masyarakat terhadap profesi akuntan mengalami perubahan akibat dari jumlah skandal keuangan beberapa perusahaan. Hilangnya kepercayaan masyarakat terhadap profesi akuntan mengakibatkan runtuhnya profesi akuntan, dimana komitmen dan profesionalisme seseorang diragukan. Salah satu cara mencegah pelanggaran akuntansi sehingga dapat mengembalikan kepercayaan masyarakat adalah dengan cara melakukan whistleblowing. Menurut Near dan Miceli dalam Elias (2008) whistleblowing adalah merupakan pelaporan yang dilakukan oleh anggota organisasi mengenai tindakkan ilegal dan tidak bermoral di dalam organisasinya kepada pihak internal maupun eksternal sehingga dapat mempengaruhi praktik kesalahan tersebut.

Penanganan kecurangan melalui tindakkan whistleblowing di Indonesia sendiri sudah berkembang sejak didirikannya lembaga pengaduan independen yang bekerja bersama Komisi Pemberantas Korupsi (KPK), Komisi Nasional Hak Asasi Manusia (Komnas HAM), Komisi Kepolisian Nasional (Kompolnas), Ombudsman. Kesadaran mengenai pentingnya pemberantasan kecurangan juga diperkuat dengan penerapan whistleblowing system di beberapa perusahaan go public seperti PT. Pertamina, United Tractors, PT. Sinar Mas, PT. Askrindo, PT Krakatau Steel, PT. Telekomunikasi Indonesia dan sebagiannya (Handika dan Sudaryanti, 2017). Sangat penting bagi mahasiswa akuntansi mengerti nilai-nilai yang harus mereka bela dan yng harus mereka hindari (Sheehan dan Schmidt, 2015). Melihat kecurangan, tindakan tidak etis, bahkan ilegal, seyogyanya seorang mahasiswa mampu menempatkan dirinya secara profesional sebagai whistleblower.

Sangat penting bagi mahasiswa akuntansi mengerti nilai-nilai yang harus mereka bela dan yang harus mereka hindari (Sheehan dan Schmidt, 2015). Melihat kecurangan, tindakan tidak etis, bahkan ilegal, seyogyanya seorang mahasiswa mampu menempatkan dirinya secara profesional sebagai whistleblower. Kemauan untuk menjalankan sesuatu sesuai dengan aturannya perlu ditumbuhkan dalam diri mahasiswa agar mempunyai keberanian menyuarakan ketidakberesan yang terjadi di universitasnya, bukan hanya diam untuk menghindari konflik. Kecurangan yang sering kali dianggap wajar karena sudah umum dilakukan membuat mahasiswa enggan untuk turut serta meberantas budaya curang. Perguruan tinggi sebagai penghasil sumber daya manusia yang profesional, diharapkan dapat memenuhi kebutuhan pasar sebagai penyedia tenaga profesional yang memiliki kualifikasi keahlian sesuai bidang ilmunya, dan juga memiliki perilaku etis tinggi (Lucyanda dan Endro, 2013).

Kecurangan atau kejadian tidak etis ini sudah menjadi bagian dari budaya pada beberapa perguruan tinggi (Kleiner dan Lord, 1999). Budaya tidak etis di lingkungan mahasiswa terjadi karena kurangnya pengetahuan, pemahaman serta kemauan untuk menerapkan nilai-nilai moral yang sudah mereka dapatkan dari keluarga maupun pendidikan formal di kampus. Komitmen profesional dalam beberapa penelitian ditemukan memiliki peran dalam tindakkan whistleblowing. Komitmen profesional merupakan suatu tanggung jawab, ikatan, loyalitas, pengorbanan, keterlibatan seorang individu dalam organisasinya. Komitmen terhadap profesi dapat diwujudkan dengan adanya suatu motivasi diri yang mendorong untuk mengaspirasikan segala ide dan gagasan yang timbul dibantu dengan supervisi yang kompeten akan menghasilkan suatu kepuasan terhadap perkerjaanya (Sary dkk, 2015). Segala perilaku etis dan bermoral yang dilakukan seseorang tentu tidak lepas dari pengendalian atas diri sendiri atau locus of control. (Sagone, Elvira, dan Caroli 2014) mendefinisikan bahwa locus of control sebagai ciri kepribadian yang mengacu pada persepsi individu bahwa keyakinan tentang hasil tindakkan kita 
bergantung pada apa yang kita lakukan (internal) atau pada apa yang terjadi diluar kendali pribadi kita (eksternal) yang dapat berupa takdir atau keberuntungan.

Sosialisasi antisipatif didefinisikan sebagai proses pengadopsian sikap dan prilaku suatu kelompok tertentu yang dilakukan oleh individu sebelum mereka tergabung ke dalam kelompok tersebut (Merton dan Rossi, 1968 dalam Elias, 2008). Tujuan penelitian ini untuk mengetahui "Pengaruh Komitmen Profesional, Locus of control, dan Sosialisasi Antisipatif Mahasiswa Akuntansi Terhadap Whistleblowing

\section{REVIU LITERATUR DAN HIPOTESIS \\ Teori Tindakan Beralasan (Theory of Reasoned Action)}

Teori tindakan beralasan menjelaskan bahwa minat merupakan sebuah fungsi dari dua penentu dasar yang berhubungan dengan faktor pribadi dan pengaruh sosial (Jogiyanto, 2007). Faktor pribadi dalam konteks teori ini adalah sikap individu terhadap perilaku, sedangkan pengaruh sosial yang dimaksud adalah norma subyektif. Teori tindakan beralasan berlaku bagi individu yang memiliki kebebasan dalam memilih tindakan yang akan dilakukan.

Miller (2005) mendefinisikan tiga komponen yang terdapat dalam teori ini. Sikap terhadap perilaku tertentu yang dinilai dari evaluasi seseorang terhadap sebuah perilaku tertentu yang dinilai dari evaluasi terhadap seseorang keyakinan tersebut (individual reasoning). Sikap terhadap perilaku dicontohkan dengan keyakinan bahwa olahraga baik untuk kesehatan, membuat seseorang terlihat bugar dan memiliki tubuh proporsional. Meskipun demikian olahraga memerlukan terlalu banyak waktu serta membuat lelah. Masing-masing keyakinan ini dapat diberi bobot pertimbangan, contohnya kesehatan jauh lebih penting dibandingkan persoalan mengenai waktu dan ketidaknyamanan yang ditimbulkan.

\section{Komitmen Profesional}

Komitmen profesional merupakan bentuk kecintaan seseorang terhadap profesi yang dijalani. Bentuk tanggung jawab, rasa kepedulian, dan sikap mempertahankan nilai-nilai yang terkandung dalam sebuah profesi menjadikan individu mampu membentuk komitmen yang kuat (Elias 2008). Adanya komitmen profesional melibatkan keyakinan dan penerimaan individu terhadap nilai-nilai dan tujuan-tujuan profesi, beserta usaha yang dicurahkan dalam menjalankan profesi.

Kaitanya dengan tindakan whistleblowing berdasarkan penelitian (Mela, Zarefar, dan Andreas 2016) komitmen profesional memiliki pengaruh terhadap keputusan seseorang untuk melakukan tindakan whistleblowing. Dijelaskan bahwa semain kuat profesionalitas yang dimiliki seorang individu, maka semakin tinggi kepedulian terhadap nilai-nilai yang terkandung dalam profesi tersebut, sehingga ketika terjadi ketidakberesan dalam organisasi kemauan untuk mengkoreksi dan melaporkan tindak kecurangan akan semakin tinggi. (Sari dan Herry 2014) dalam penelitiannya menjelaskan bahwa terdapat beberapa komponen profesionalisme yang dijelaskan oleh Hall dalam buku karangan Kabers dan Forgathy. Lima komponen tersebut antara lain, afiliasi dengan komunitas, kewajiban social, dedikasi terhadap pekerjaan, keyakinan terhadap peraturan sendiri atau profesi, tuntutan untuk mandiri

\section{Locus of Control}

Locus of control menurut (Sagone, Elvira, dan Caroli 2014) didefenisikan sebagai ciri kepribadian yang mengacu pada persepsi individu terhadap suatu peristiwa dapat terjadi karena ditentukan secara internal oleh tingkah lakunya atau sebaliknya suatu peristiwa terjadi 
disebabkan oleh keadaan eksternal seperti takdir, maupun keberuntungan. Locus of control merupakan keyakinan seseorang tentang apakah suatu hasil tindakan yang dilakukan individu bergantung pada apa yang dilakukan (berorientasi pada pengendalian internal) atau bergantung pada kejadian diluar kendali pribadi individu (berorientasi pada pengendalian eksternal). Locus of control diartikan sebagai watak kepribadian yang memberikan pengaruh pada pengambilan keputusan dan tingkah laku seseorang (Chiu 2002).

Locus of control dibedakan menjadi dua, yaitu locus of control internal dan locus of control external. Individu dengan locus of control internal mempercayai bahwa segala sesuatu yang terjadi dikehidupannya baik keberhasilan maupun kegagalan merupakan kendali yang berasal dari dirinya sendiri, kemampuan yang dimiliki, dan perilaku yang mereka buat. Sedangkan individu dengan locus of control external beranggapan bahwa segala sesuatu yang terjadi dikehidupannya baik keberhasilan maupun kegagalan dikontrol dari keadaan sekitar berupa nasib, takdir, dan keberuntungan semata.

Seseorang yang dengan yakin mampu mengendalikan tujuannya dapat dikatakan memiliki internal locus of control, sedangkan individu yang menganggap hidupnya hanya dikendalikan oleh kekuatan pihak luar disebut memiliki external locus of control. Kekuatan locus of control dikaitkan dengan keputusan melakukan whistleblowing terletak pada kemampuan untuk mengendalikan lingkungan sekitar sesuai dengan tujuan atau malah sebaliknya, hanya dikendalikan oleh lingkungan.Locus of control yang berbeda akan menunjukkan motivasi dan kinerja yang berbeda. Seseorang dengan internal locus of control akan merasa mempunyai kekuatan untuk mengendalikan segala sesuatu yang terjadi di kehidupannya baik sesuatu yang baik maupun buruk. Namun, seseorang dengan external locus of control akan cenderung apatis dengan keadaan sekitar dan hanya mengikuti arus kemana lingkungan akan membawa nasibnya.

\section{Sosialisasi Antisipatif}

(Elias 2008) mendefinisikan sosialisasi antisipatif sebagai pembentukan keyakinan dan sikap yang dianut suatu kelompok tertentu sebagai persiapan untuk masuk menjadi bagian dari anggota kelompok tersebut. Sosialisasi antisipatif adalah proses mengadopsi sikap dan kepercayaan dari sebuah kelompok sebelum seseorang menjadi bagian dari kelompok tersebut (Mela, Zarefar, dan Andreas 2016). Ditambahkan dalam penelitian yang dilakukan oleh (Sang 2009) aspek-aspek yang disosialisasikan meliputi sikap-sikap, norma-norma, dan nilai-nilai dari sebuah profesi yang akan ditekuni seseorang.

Sosialisasi antisipatif terjadi saat terjadinya transfer ilmu mengenai wewenang dan tanggung jawab yang ada pada profesi yang akan dijalani harus dilakukan secara benar, mengingat efek jangka panjang yang timbul akbiat proses pemahaman ini. Penyampaian kode etik, pendidikan tentang nilai-nilai yang terkandung dalam profesi akan menumpuk rasa tanggung jawab dan kesungguhan dalam menjalankan profesinya. Nilai-nilai yang ditanamkan bahkan jauh sebelum masuk kedalam profesi tersebut diharapkan tetap mampu dijalankan pada lingkungan kerja sesungguhnya sehingga tidak akan terjadi perilaku yang menyimpang.

Kaitannya dengan mahasiswa akuntansi, proses sosialisasi antisipatif dimulai saat mahasiswa belajar memprioritaskan kebutuhan pengguna laporan keuangan (Mela, Zarefar, dan Andreas 2016). Bagi akuntan pendidik, pembelajaran mengenai kebutuhan pengguna laporan keuangan yang harus dilindungi kepentingannya mengingat bahwa user tersebut mengandalkan 
laporan keuangan sebagai dasar pengambilan keputusan. Selain itu, melalui laporan keuangan itulah seorang akuntan dapat merepresentasikan tingkat profesionalitasnya.

\section{Pengaruh Komitmen Profesional Terhadap Whistleblowing}

Pengaruh komitmen profesional terhadap keputusan seseorang melakukan tindakan whistleblowing dibuktikan pada penelitian (Mela, Zarefar, dan Andreas 2016) bahwa semakin besar komitmen yang ditanamkan dalam profesi yang mereka jalani mereka akan cenderung melakukan tindakkan preventif untuk menyelamatkan organisasinya sebagai cerminan rasa kepemilikan dan tanggung jawab terhadap tugas yang mereka lakukan. Individu yang memiliki komitmen yang tinggi akan cenderung melakukan upaya-upaya positif demi menyelamatkan organisasi dari tindak kecurangan. Berdasarkan penjelasan di atas maka disusun hipotesis sebagai berikut:

$\mathbf{H}_{1}$ : Komitmen profesional berpengaruh positif terhadap whistleblowing.

\section{Pengaruh Internal Locus Of Control Terhadap Whistleblowing}

Pengertian locus of control internal menurut (Sagone, Elvira, dan Caroli 2014) merupakan keyakinan seorang individu terhadap kemampuan untuk mengontrol nasib mereka sendiri. Seseorang yang mampu memegang kontrol atas apa yang terjadi pada kehidupannya akan lebih mempresentasikan ketaatan dan berusaha mencegah bentuk kecurangan karena mereka yakin mampu mengubah keadaan melalui perilaku positif. Seseorang yang memiliki internallocus of control akan menganggap whistleblowing sebagai tindakan benar yang seharusnya dilakukan dengan tujuan untuk mengembalikan kepercayaan publik dan tindakan preventif agar tindak kecurangan tersebut tidak terulang (Joneta, 2016). Berdasarkan penjelasan di atas maka di ajukan hipotesis sebagai berikut:

$\mathbf{H}_{2}$ : internal locus of control berpengaruh positif terhadap whistleblowing.

\section{Pengaruh External Locus Of Control Terhadap Whistleblowing}

Pengertian dari (Sagone, Elvira, dan Caroli 2014) adalah keyakinan seseorang tentang peruntungan dan nasib seseorang akan menentukan kejadian-kejadian yang terjadi dalam kehidupannya baik kesuksesan maupun kegagalan. Pola pikir dari mahasiswa dengan tingkat external locus of control tinggi akan cenderung pesimis dengan kemampuannya dan cenderung berpikir bahwa seberapa keras usaha yang dilakukan ketika dihadapkan dengan kehidupan sosial yang tidak mendukung akan bersikap persisten dan tidak memiliki pengharapan yang tinggi untuk mengubah suatu keadaan, sehingga menganggap bahwa tindakkan whistleblowing adalah tindakkan yang sia-sia. Berdasarkan penjelasan di atas maka disusunlah hipotesis sebagai berikut:

H3: external locus of control berpengaruh negatif terhadap whistleblowing.

\section{Pengaruh Sosialisasi Antisipatif Mahasiswa Akuntansi Terhadap Whistleblowing}

Telah dijelaskan oleh Elias (2006) bahwa sosialisasi antisipatif merupakan komponen yang penting dalam membentuk persepsi seseorang terhadap profesinya. Sehingga, dengan adanya sosialisasi antisipatif akan membantu seseoran untuk patuh terhadap standar etika dalam profesinya. Elias (2008) menemukan bahwa semakin tinggi tingkat sosialisasi antisipatif seseorang, maka makin tinggi pula kecenderungan orang tersebut melakukan whistleblowing. Berdasarkan penjelasan di atas maka disusunlah hipotesis sebagai berikut : 
H4: sosialisasi antisipatif berpengaruh positif terhadap whistleblowing.

\section{Kerangka konseptual}

Berdasarkan penjelasan dari berbagai teori-teori yang telah dijabarkan diatas, maka penulis menyusun kerangka konseptual untuk penelitian ini sebagai berikut:

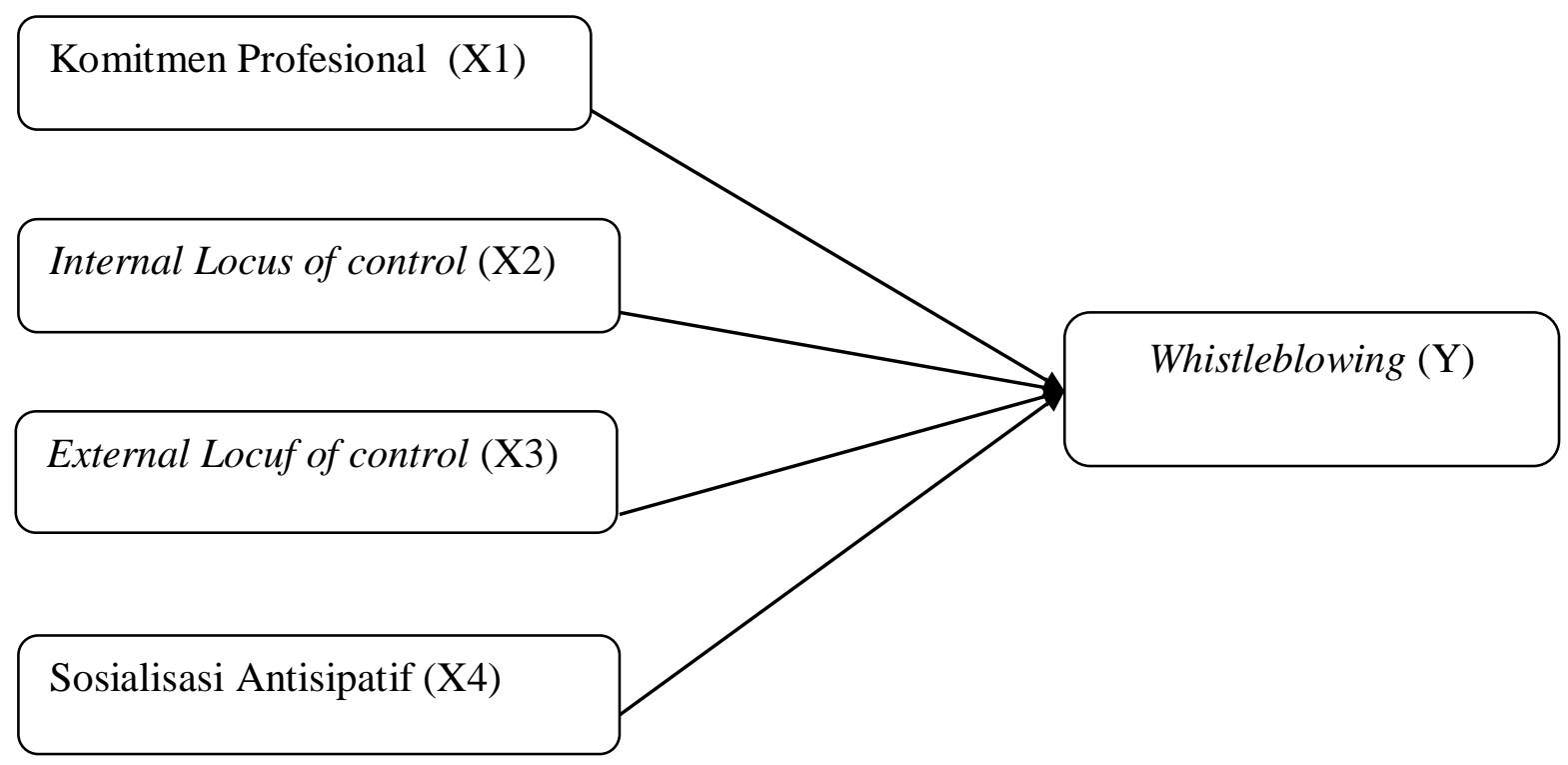

\section{Gambar 1. Kerangka konseptual}

\section{METODE PENELITIAN}

Jenis penelitian ini tergolong penelitian kuantitatif. Penelitian ini dimaksudkan untuk mengetahui pengaruh komitmen profesional, locus of control dan sosialisasi antisipatif mahasiswa akuntansi terhadap whistleblowing. Populasi dan sampel dalam penelitian ini adalah mahasiswa akuntansi S1 tahun masuk 2014 dan 2015 yang sudah mengikuti mata kuliah auditing. Jenis data yang digunakan dalam penelitian ini adalah data primer. Teknik yang digunakan dalam pengumpulan data untuk penelitian inidengan menggunakan kuesioner.

Variabel dependen dalam penelitian ini adalah whistleblowing (Y). Dimana variabel denpenden ini adalah variabel terikat. Variabel indenpenden dalam penelitian ini adalah komitmen profesional (X1), locus of control (X2) dan sosialisasi antisipatif mahasiswa akuntansi (X3). Tipe variabel ini adalah tipe variabel yang menjelaskan atau mempengaruhi variabel terikat.

\section{HASIL DAN PEMBAHASAN}

\section{Hasil Penelitian}

Populasi dalam penelitian ini adalah Mahasiswa Akuntansi S1 Fakultas Ekonomi UNP dengan jumlah 100 orang. Berikut datadan jumlah masing-masing Mahasiswa Akuntansi S1 yang menjadi responden dalam penelitian ini. 
Tabel 1

Daftar Mahasiswa Akuntansi S1

\begin{tabular}{|l|l|l|}
\hline No & Tahun Angkatan & $\begin{array}{l}\text { Jumlah } \\
\text { responden }\end{array}$ \\
\hline 1 & Mahasiswa Akuntansi S1 Angkatan tahun 2014 & 34 \\
\hline 2 & Mahasiswa Akuntansi S1 Angkatan tahun 2015 & 66 \\
\hline & Total & $\mathbf{1 0 0}$ \\
\hline
\end{tabular}

Berdasarkan Tabel data Mahasiswa akuntansi S1 maka terdapat 100 responden dalam penelitian ini. Kuesioner yang dibagikan sebanyak 100, ada kuesioner yang tidak di kembalikan dan kuesioner yang tidak dapat diolah sebanyak 4 rangkap.

Tabel 2

Tingkat Pengembalian Kuisioner

\begin{tabular}{|l|l|l|}
\hline No. & Keterangan & Jumlah \\
\hline 1. & Jumlah kuesioner yang tersebar & 100 \\
\hline 2. & Jumlah kuesioner yang kembali & 100 \\
\hline 3. & Jumlah kuesioner yang tidak dapat diolah & 4 \\
\hline 4. & Jumlah kuesioner yang dapat diolah & 96 \\
\hline & Responden Rate & $96 \%$ \\
\hline
\end{tabular}

Sumber: Data Primer yang diolah tahun 2018

\section{Uji Validitas}

Berikut tabel hasil olah data penulis untuk diuji validitas sebagai berikut ini :

Tabel 3

Ui Validitas

Nilai Corrected Item-Total Correlation Terkecil

\begin{tabular}{|l|l|}
\hline Instrumen Variabel & $\begin{array}{l}\text { Nilai Corrected Item-Total } \\
\text { Correlation terkecil }\end{array}$ \\
\hline Whistleblowing $(\mathrm{Y})$ & 0,265 \\
\hline Komitmen Profesional $\left(\mathrm{X}_{1}\right)$ & 0,747 \\
\hline Locus Of Control Internal $\left(\mathrm{X}_{2}\right)$ & 0,600 \\
\hline Locus Of Control External $\left(\mathrm{X}_{3}\right)$ & 0,650 \\
\hline Sosialisasi Antisipatif Mahasiswa Akuntansi $(\mathrm{X} 4)$ & 0,686 \\
\hline
\end{tabular}

Sumber: Data Primer yang diolah tahun 2018.

Jadi dapat dikatakan bahwa semua item pernyataan variabel X1,X2,X3 dan X4 adalah valid.

\section{Uji Reliabilitas}

Berikut tabel hasil olah data penulis untuk uji reliabilitas sebagai berikut : 
Tabel 4

Uji Reliabilitas

\begin{tabular}{lll}
\hline Variabel & Nilai Cronbach Alpha & Keterangan \\
\hline X1 & 0,741 & Reliabel \\
X2 & 0,860 & Reliabel \\
X3 & 0,727 & Reliabel \\
X4 & 0,830 & Reliabel \\
Y & 0,824 & Reliabel \\
\hline
\end{tabular}

Sumber :Hasil olahan penulis 2018

Hasil tersebut menunjukkan bahwa semua variabel mempunyai Cronbach Alpha yang cukup besar di atas 0,1986. Sehingga item-item pada masing-masing konsep variabel tersebut layak digunakan sebagai alat ukur.

\section{Uji Normalitas}

Berikut hasil uji normalitas berdasarkan olah data dengan software SPSS

Tabel 5

Uji Normalitas

\begin{tabular}{|ll|l|}
\hline & & Unstandardized Residual \\
\hline $\mathrm{N}$ & & 96 \\
Norma; Parametersa,b & Mean & .0000000 \\
& Std. Deviation & 3.84314941 \\
& Absolute & .078 \\
Most Extreme Differences & Positive & .078 \\
& Negative & -.056 \\
Kolmogrov-Smirnov Z & & .764 \\
Asymp. Sig. (2-tailed) & .604 \\
\hline
\end{tabular}

Test distribution is Normal. Calculated from data.

Sumber : Hasil olahan penulis 2018

Berdasarkan tabel di atas terlihat bahwa hasil uji normalitas menunjukkan level signifikan lebih besar dari $\alpha(\alpha=0,05)$ yaitu $0,604>0,05$ yang berarti bahwa data terdistribusi secara normal

\section{Uji Multikolinearitas}

Berikut hasil uji multikolinearitas berdasarkan olah data dengan software SPSS yang penulis lakukan :

\section{Tabel 6}

\section{Uji Multikolinearitas}

\begin{tabular}{|l|l|l|}
\hline Model & Tolerance & VIF \\
\hline Constant) & & \\
Komitmen profesional & .641 & 1.557 \\
Internal locus of control & .616 & 1.623 \\
External locus of control & .968 & 1.033 \\
Sosialisasi Antisipatif & .495 & 2.019 \\
\hline
\end{tabular}


Dari tabel diatas dapat dilihat bahwa ketiga variabel memiliki nilai tolerance $>0,10$ dan nilai VIF keempat variabel $<10$ maka dapat dikatakan tidak terdapat korelasi variabel-variabel bebas antara satu dengan lainnya atau variabel independen pada penelitian ini bebas multikolinearitas.

\section{Uji Heteroskedastisitas}

Berikut hasil uji heteroskedastisitas berdasarkan olah data dengan software SPSS yang penulis lakukan.

Tabel 7

Uji Heterokedastisitas

Coefficients $^{\mathrm{a}}$

\begin{tabular}{|cl|l|l|l|l|l|}
\hline Model & & \multicolumn{2}{l|}{$\begin{array}{l}\text { Unstandardized } \\
\text { Coefficients }\end{array}$} & $\begin{array}{l}\text { Standardized } \\
\text { Coefficients }\end{array}$ & & T \\
\cline { 3 - 5 } & & B & Std. Error & Beta & & \\
\hline \multirow{4}{*}{1} & (Constant) & 1.868 & 2.231 & & .837 & .405 \\
& Komitmen Profesional & -.177 & .091 & -.246 & -1.947 & .055 \\
& Internal locus of control & .107 & .122 & .114 & .881 & .381 \\
& External locus of control & -.056 & .062 & -.093 & -.903 & .369 \\
& Sosialisasi antisipatif & .178 & .122 & .211 & 1.463 & .147 \\
\hline
\end{tabular}

Sumber :hasil olahan penulis dengan software SPSS ver 21

Berdasarkan tabeldiatas dapat dilihat bahwa hasil perhitungan masing-masing variabel menunjukkan bahwa level sig > 0,05 yaitu 0,055>0,05 untuk variabelkomitmen profesional, 0,381 > 0,05 untuk variabel internal locus of control, 0,369>0,05 untuk variabel external locus of control, 0,147 > 0,05 untuk variabel sosialisasi antisipatif. Sehingga penelitian ini bebas dari gejala heterokedastisitas dan layak untuk diteliti.

Koefisien Determinasi (Adjusted $R^{2}$ )

Berikut hasil uji koefisien determinasi berdasarkan olah data dengan software SPSS yang penulis lakukan :

Tabel 8

Koefisien Determinasi

\begin{tabular}{|c|c|c|c|c|}
\hline Model & $\mathrm{R}$ & R Square & $\begin{array}{l}\text { Adjusted } \\
\text { Square }\end{array}$ & $\mathrm{R}$ Std. Error of the Estimate \\
\hline 1 & $.463^{\mathrm{a}}$ & .214 & .179 & 3.92671 \\
\hline
\end{tabular}

a. Predictors: (Constant), komitmen profesional, internal locus of control, external locus of control, sosialisasi antisipatif.

Berdasarkan tabel di atas terlihat bahwa besarnya nilai adjusted $R$ square adalah 0,566 yang bermakna bahwa kemampuan variabel komitmen profesional (X1), internal locus of control (X2), external locus of control (X3), sosialisasi antisipatif (X4) menjelaskan variabel penilaian whistleblowing (Y) sebesar $17,9 \%$ sedangkan sisanya sebesar $83,1 \%$ dipengaruhi oleh variabel diluar model penelitian. 
Uji Simultan (Uji F)

Berikut hasil uji simultan berdasarkan olah data dengan software SPSS yang penulis lakukan:

Tabel 9

Uji Simultan

\begin{tabular}{|c|c|c|c|c|c|c|}
\hline \multicolumn{7}{|c|}{ ANOVA $^{\mathrm{a}}$} \\
\hline Model & & Sum of Squares & $\mathrm{df}$ & Mean Square & $\mathrm{F}$ & Sig. \\
\hline \multirow{3}{*}{1} & Regression & 382.025 & 4 & 95.506 & 6.194 & $.000^{\mathrm{b}}$ \\
\hline & Residual & 1403.131 & 91 & 15.419 & & \\
\hline & Total & 1785.156 & 95 & & & \\
\hline
\end{tabular}

a. Dependent Variable: whistleblowing

b. Predictors: (Constant), komitmen profesional, internal locus of control, external locus of control, sosialisasi antisipatif

Hasil statistic menunjukan bahwa nilai sig $0,000<0,05$. Hal ini berarti bahwa secara simultan (bersama-sama) variabel komitmen profesional, internal locus of control, external locus of control, sosialisasi antisipatif terhadap whistleblowing

\section{Analisis Regresi Berganda}

Berikut hasil uji regresi berganda berdasarkan olah data dengan software SPSS yang penulis lakukan :

Tabel 10

\section{Analisis Regresi Berganda}

Coefficients $^{\mathrm{a}}$

\begin{tabular}{|ll|l|l|l|l|l|}
\hline \multirow{2}{*}{ Model } & & \multicolumn{2}{|c|}{$\begin{array}{l}\text { Unstandardized } \\
\text { Coefficients }\end{array}$} & $\begin{array}{l}\text { Standardized } \\
\text { Coefficients }\end{array}$ & \multirow{2}{*}{ Sig. } \\
\cline { 2 - 5 } & & B & Std. Error & Beta & & \\
\hline \multirow{4}{*}{1} & (Constant) & 29.024 & 3.999 & & 7.257 & .000 \\
& Komitmen profesional & .340 & .163 & .241 & 2.082 & .040 \\
& Internal locus of control & .450 & .218 & .244 & 2.064 & .042 \\
& External locus of control & -.224 & .112 & -.189 & -2.004 & .048 \\
& Sosialisasi antisipatif & .098 & .219 & .059 & .450 & .654 \\
\hline
\end{tabular}

Sumber: Data Primer yang diolah tahun 2018

Berdasarkan tabel di atas dapat dianalisis model estimasi sebagai berikut:

$$
\mathrm{Y}=29,024+0,340 \mathrm{X} 1+0,450 \mathrm{X} 2+0,224 \mathrm{X} 3+0,098 \mathrm{X} 4+e
$$

Keterangan:

$\mathrm{Y}=$ Whistleblowing

$\mathrm{X} 1=$ Komitmen profesional

$\mathrm{X} 2=$ Internal locus of control

$\mathrm{X} 3=$ External locus of control

$\mathrm{X} 4=$ Sosialisasi antisipatif 
Dari persamaan diatas dapat dijelaskan bahwa:

a) Nilai konstanta sebesar 29,024ini mengidentifikasikan bahwa adanya pengaruh dari variabel bebas yaitu komitmen profesional, internal locus of control, external locus of control, sosialisasi antisipatif, maka whistleblowing akan bernilai sebesar 29,024.

b) Koefisien Komitmen profesional sebesar 0,340 ini mengidentifikasikan jika variabel komitmen profesional menurun satu-satuan maka variabel whistleblowing akan menurun sebesar 0,340 dengan asumsi variabel lain konstan.

c) Koefisien Internal locus of control sebesar 0,450 mengidentifikasikan jika variabel internal locus of control menurun satu-satuan maka variabel whistleblowing meningkatsebesar 0,450 dengan asumsi variabel lain konstan.

d) Koefisien External locus of controlsebesar -0,224 mengidentifikasikan jika external locus of control menurun satu-satuan maka variabel whistleblowing menurun sebesar 0,224 dengan asumsi variabel lain konstan.

e) Koefisien Sosialisasi antisipatif sebesar 0,098 mengidentifikasi jika sosialisasi antisipatif meningkat satu-satuan maka variabel whistleblowing akan meningkat sebesar 0,098 dengan asumsi variabel lain konstan.

\section{Uji Hipotesis (t-test)}

Uji t statistik ( $t$-test) bertujuan untuk mengetahui hubungan yang signifikan dari masing-masing variabel bebas terhadap variabelterikatnya. Berdasarkan hasil analisis pada tabelmaka dapat diketahui pengaruh variabel independen secara parsial terhadap variabel dependen adalah sebagai berikut:

\section{Pengujian Hipotesis 1}

Pengujian hipotesis dilakukan dengan membandingkan nilai sig < alpha 0,05. Nilai sig 0,040< alpha 0,05 serta nilai koefisien beta bertanda positif sebesar 0,340. Sehingga dinyatakan komitmen profesional berpengaruh signifikan positif terhadap whistleblowing. Dengan demikian hipotesis pertama $\left(\mathrm{H}_{1}\right)$ diterima.

\section{Pengujian Hipotesis 2}

Pengujian hipotesis dilakukan dengan membandingkan nilai sig < alpha 0,05. Nilai sig 0,042 > alpha 0,05 serta nilai koefisien beta bertanda positif sebesar 0,450. Sehingga dinyatakan internal locus of control terbukti berpengaruh signifikan positif terhadap whistleblowing. Dengan demikian hipotesis kedua $\left(\mathrm{H}_{2}\right)$ diterima.

\section{Pengujian Hipotesis 3}

Pengujian hipotesis dilakukan dengan membandingkan nilai sig < alpha 0,05. Nilai sig 0,048< alpha 0,05 serta nilai koefisien beta bertanda negatif sebesar -0,224. Hal ini menunjukkan bahwa penelitian ini dapat membuktikan variabel external locus of control berpengaruh signifikan negatif terhadap whistleblowing. Dengan demikian hipotesis ketiga $\left(\mathrm{H}_{3}\right)$ diterima.

\section{Pengujian Hipotesis 4}

Pengujian hipotesis dilakukan dengan membandingkan nilai sig < alpha 0,05. Nilai sig 0,654 > alpha 0,05, serta nilai koefisien beta bertanda positif sebesar 0,098. Hal ini menunjukkan bahwa penelitian ini tidak dapat membuktikan variabel sosialisasi antisipatif berpengaruh signifikan positif terhadap whistleblowing. Dengan demikian hipotesis ke empat ditolak. 


\section{PEMBAHASAN}

\section{Pengaruh Komitmen Profesional Terhadap Whistleblowing}

Hasil penelitian membutktikan bahwa variable komitmen profesional berpengaruh signifikan positif terhadap whistleblowing. Semakin tinggi tingkat komitmen profesional seseorang maka semakin besar potensi melakukan whistleblowig. Penelitian ini konsisten dengan penelitian Sugianto (2010), Elias (2008), Prasasti (2017), Yulianto (2015). Tingkat komitmen profesional mungkin merupakan refleksi hubungan auditor dengan lingkungan industri/profesional, hal tersebut dikarenakan salah satu aspek komitmen profesional adalah penerimaan norma-norma profesional dan tujuan.

\section{Pengaruh Internal Locus Of Control Terhadap Whistleblowing}

Hasil penelitian ini membuktikan bahwa variabel internal locus of control berpengaruh positif terhadap whistleblowing. Penelitan ini mendukung penelitan yang dilakukan oleh Astuti (2018), internal locus of control merupakan kendali individu atas segala sesuatu merupakan hasil dari kemampuan dirinya, sehingga merekalah yang menjadi penentu atas nasib mereka sendiri bukan orang lain, lingkungan, atau keberuntungan semata.

Implikasinya pada penelitian ini diketahui bahwa internal locus of control tinggi akan cenderung melakukan whistleblowing karena mereka yakin merekalah yang mempunyai kemampuan dan kemampuan mereka yang akan menentukan nasib mereka.

\section{Pengaruh External Locus Of Control Terhadap Whistleblowing}

Hasil penelitian ini membuktikan bahwa variabel external locus of control berpengaruh negatif terhadap whistleblowing. External locus of control merupakan keyakinan seseorang tentang peruntungan dan nasib seseorang akan menentukan kejadian-kejadian yang terjadi dalam kehidupannya baik kesuksesan maupun kegagalan. Penelitian ini mendukung penelitian yang dilakukan Astuti (2018).

Berdasarkan hasil penelitian ini, ditunjukkan bahwa external locus of control memiliki pengaruh terhadap whistleblowing. Pengaruh eksternalitas diluar dari diri seorang mahasiswa mampu mendorong mahasiswa untuk melakukan tindakan whistleblowing. Pertimbangan diluar keyakinan individu seperti lingkungan yang tidak memungkinkan untuk berbuat curang, tertutupnya kesempatan untuk melakukan tindakkan imoral dapat menurunkan tingkat kecurangan yang terjadi. Melalui jawaban responden mengindikasi bahwa external locus of control memiliki pengaruh terhadap whistleblowing dilihat dari pengaruh luar yang kuat akan melatarbelakangi tindakkan yang dilakukan mahasiswa.

\section{Pengaruh Sosialisasi Antisipatif Mahasiswa Akuntansi Terhadap Whistleblowing}

Hasil penelitian ini membuktikan bahwa variabel sosialisasi antisipatif mahasiswa akuntansi tidak berpengaruh terhadap whistleblowing. Hasil penelitian ini sejalan dengan penelitian yang dilakukan oleh (Mela, Zarefar, dan Andreas 2016) yang menjelaskan bahwa sosialisasi antisipatif mahasiswa akuntansi tidak berpengaruh terhadap whistleblowing.

Implikasinya dari penelitian ini, menunjukan tidak adanya pengaruh antara sosialisasi antisipatif dengan keinginan menjadi whistleblower. kaitanya dengan pelaporan tindakkan kecurangan melalui jawaban responden mengenai sosialisasi antisipatif, dapat diindikasi bahwa responden cukup memahami pentingnya perilaku whistleblowing apabila menemukan kecurangan yang terjadi. Namun, terdapat indikasi bahwa faktor lingkungan yang kurang 
mendukung dilakukanya whistleblowing akan membuat whistleblower berpikir ulang untuk melakukan tindakkan tersebut untuk menjamin kehidupan bersosial. Proses sosialisasi antisipatif sejatinya merupakan proses yang berkesinambungan, sehingga dampaknya pun tidak serta merta terlihat, mengingat pembentukan karakter dalam etika profesi tidak terbentuk dalam waktu singkat (Astuti, 2018).

\section{KESIMPULAN, KETERBATASAN DAN SARAN \\ Kesimpulan}

Berdasarkan hasil temuan penelitian dan pengujian hipotesis yang telah dijelaskan pada bagian sebelumnya, maka dapat disimpulkan bahwa:

1. Komitmen professional berpengaruh signifikan positif terhadap penilaian whistleblowing. Hipotesis pertama diterima.

2. Internal locus of control berpengaruh signifikan positif terhadap whistleblowing. Hipotesis kedua diterima.

3. External locus of control berpengaruh signifikan negative terhadap whistleblowing. Hipotesis ketiga diterima.

4. Sosialisasi antisipatif mahasiswa akuntansi tidak berpengaruh positif terhadap whistleblowing. Hipotesis keempat ditolak.

5. Nilai Adjusted R-Square sebesar 17,9 \% yang bermakna kemampuan variable komitmen profesional, internal locus of control, external locus of control, sosialisasi antisipatif mahasiswa akuntansi menjelaskan variable whistleblowing 17,9\% sedangkan 83,1\% lain dipengaruhi oleh variabel lain di luar penelitian.

\section{Keterbatasan}

Penelitian ini memiliki keterbatasan yang memungkinkan dapat melemahkan hasil penelitian. Beberapa keterbatasan tersebut adalah :

1. Metode pemilihan sampel dalam penelitian ini adalah purposive sampling. Keunggulan metode ini adalah peneliti dapat memilih sampel yang tepat, sehingga peneliti akan memperoleh data yang memenuhi kriteria untuk di uji. Namun, penggunaan metode purposive sampling berakibat pada kurangnya kemampuan generalisasi dari hasil penelitian.

2. Masih ada sejumlah variabel lain yang belum digunakan dalam penelitian ini sedangkan variabel tersebut memiliki pengaruh terhadap whistleblowing.

3. Sampel dalam penelitian ini adalah mahasiswa akuntansi sedangkan lebih tepat yang menjadi sampel dalam penelitian ini adalah akuntan publik baik auditor Kantor akuntan publik (KAP) maupun auditor pemerintah.

\section{Saran}

Berdasarkan pembahasan, kesimpulan dan kelemahan yang terdapat dalam penelitian ini, maka diharapkan peneliti selanjutnya dapat memberikan hasil penelitian yang lebih berkualitas dengan mempertimbangkan beberapa hal di bawah ini:

1. Kembangkan pengetahuan tentang profesi Akuntansi.

2. Tingkatkan kemampuan atau skill agar imbalan yang diterima dapat lebih meningkat.

3. Tingkatkan sosialisasi dalam pergaulan serta tingkatkan kemampuan agar lebih mudah untuk dapat pekerjaan. 


\section{DAFTAR PUSTAKA}

Ahmad, S. A., Smith, M., Ismail, Z., \& Yunos, R. M. (2011). Internal whistleblowing intentions: Influence of internal auditors' demographic and individual factors. Annual Summit on Business and Entrepreneurial Studies (ASBES 2011) Proceeding.

Ajzen, I. (1991). From intentions to actions: A theory of planned behavior.

Astuti, E. Kusuma. 2018. Pengaruh Etika, Komitmen Profesional, Sosialisasi Antisipatif, dan Locus Of Control Mahasiswa terhadap Whistleblowing." Skripsi. Yogyakarta: Fakultas Ekonomi, Universitas Islam Indonesia.

Brabeck, M. M. (1984). Ethical Characteristics of Whistle-Blowers. Journal of Research in Personality. 18: 41-53.

Chiu, R. K. (2002). Ethical Judgement, Locus of Control, and Whistleblowing Intention: A case study of mainland Chinese MBA students. Managerial Auditing Journal, 17(9), 581-587.

Clikeman, Paul M. and Steven L.H. (2000). The Socialization of Undergraduate Accounting Students. Issues in Accounting Education 15(1), 1-17 .Retrieved (http://search.ebscohost.com/login.aspx?direct=true \&db=bth\&AN=301286\&site=ehostlive).

Elias, R. Z. (2006). The impact of professional commitment and anticipatory socialization on accounting students ethical orientation. Journal of Business Ethics, 68(1), 83-90.

Elias, R. Z. (2008). Auditing Students Professional Commitment and Anticipatory Socialization and Their Relationship to Whistleblowing. Managemerial Auditing Journal, 23(3), 283294.

Fatimah, 2018. Pengaruh Komitmen Organisasi, Pertimbangan Etis, Religiusitas dan Intensitas Moral Terhadap Intensi Whistleblowing Pada Kantor Inspektorat di Kota Surakarta dan Kabupaten Sukoharjo. Skripsi, Surakarta: Fakultas Ekonomi dan Bisnis Islam, Institut Agama Islam Negeri Surakarta.

Ghozali, I. (2011). Aplikasi Analisis Multivatiate dengan Program IBM SPSS 19. Semarang : Badan Penerbit Universitas Diponegoro.

Handika, Mellisa F.D dan Dwiyani S. (2017). Analisis Faktor Faktor Yang Mempengaruhi Niat Mahasiswa Melakukan Tindakan Whistleblowing (Studi Pada Mahasiswa Akuntansi STIE Asia Malang). Jurnal Jibeka 11 (1): 56-63.

Hanif, Rheny A, dan Fajar O, (2017). Pengaruh Lingkungan Etika Terhadap Niat Melakukan Whistleblowing Dengan Locus of Control Sebagai Variabel Moderasi. Jurnal Akuntansi Keuangan Dan Bisnis, 10 (2): 61-69.

Hartono, J. (2007). Metodologi Penelitian Bisnis: Salah Kaprah dan Pengalaman-Pengalaman. BPFE. Yogyakarta.

Indriantoro, N dan Supomo, B. (2002). Metodologi penelitian bisnis: Untuk akuntansi dan manajemen. Yogyakarta: BPFE.

James J. S. (1997). Ekonomi Pariwisata, Transformasi Budaya Indonesia. PT. Gramedia. Jakarta.

Jogiyanto, (2007). Sistem Informasi Keperilakuan. Edisi Revisi. Yogyakarta: Andi Offset.

Joneta, C. (2016). Pengaruh Komitmen Profesional dan Pertimbangan Etis terhadap Intensi Melakukan Whistleblowing. JOM Fekon, 3 (1), 735-748.

KBBI, 2016. Kamus Besar Bahasa Indonesia (KBBI). [Online] Available at: http://kbbi.web.id/pusat, [Diakses 21 Juni 2016]. 
KNKG. (2008). Pedoman Sistem Pelaporan Pelanggaran - SPP (Whistleblowing System WBS). Jakarta: Komite Nasional Kebijakan Governance.

Lucyanda, J. dan Gunardi E. (2013). Faktor-Faktor Yang Mempengaruhi Perilaku Etis Mahasiswa Akuntansi Universitas Bakrie. Jurnal Ekonomi Dan Ilmu Sosial 2: 1-34.

Mcdonald, G. M. (2009). An anthology of Codes of Ethics. European Business Review, Vol.21 No.4.

Mela, N.F., Arumega, Z., dan Andreas. 2016. The Relationship of Profesional Commitment of Auditing Student and Anticipatory Socialization toward Whistleblowing Intention. In 3rd Global Conference on Business and Social Science, 219:507-12.

Merdikawati, R. 2012. Hubungan Komitmen Profesi dan Sosialisasi Antisipatif Mahasiswa Akuntansi dengan Niatan Whistleblowing (Studi Empiris pada Tiga Universitas Negeri Teratas di Jawa Tengah dan D. I. Yogyakarta). Skripsi, Semarang: Fakultas Ekonomika dan Bisnis, Universitas Diponegoro.

Merdikawati, R. dan Andri, P. (2012). Hubungan Komitmen Profesi dan Sosialisasi Antisipatif Mahasiswa Akuntansi Dengan Niat Whistleblowing. Diponegoro Journal Of Accounting, 1(1), 1-10.

Miller, J.N. and Miller, J.C. (2005), Statistics and Chemometrics for Analytical Chemistry, Pearson Education, Harlow, England, pp 18-69.

Prasasti, Nur Intan. 2017. Komitmen Profesional, Sosialisasi Antisipatif, dan Locus of Control : Pengaruhnya Terhadap Perilaku Whistleblowing. Skripsi. Fakultas Ekonomi Bisnis Islam Institut Agama Islam Negeri Surakarta.

Purnamasari, D. P. P. dan H. G. 2016. Pengaruh sensitivitas etis, professional identity, dan locus of control terhadap whistleblowing intention. Proseding Akuntansi, 2(2), 955-963.

Raharjo, F.D. (2015). Faktor Yang Mempengaruhi Pelaporan Whistleblowing Internal Dengan Tingkat Pendidikan Sebagai Variabel Moderasi Persepsi Karyawan Di PT. Krakatau Steel (Persero) Tbk. Jurnal Media Riset Akuntansi, Auditing \& Informasi 15(2), 103-16.

Reginaldi. 2014. Analisis Pengaruh Remunerasi, Mutasi, Whistleblowing System, Motivasi dan Kepuasan Kerja Terhadap Prestasi Kerja dengan Komitmen Organisasi sebagai Variabel Moderasi (Studi Kasus Pada Kantor Pelayanan Pajak Pratama Lubuk Pakam). Thesis. Fakultas Ekonomi Universitas Sumatera Utara.

Riduwan dan Akdon. (2010). Rumus dan Data dalam Analisis Data Statistika. Bandung: Alfabeta

Robbins, P.S. (2008). Organizational Behaviour, Tenth Edition (Perilaku Organisasi Edisi ke Sepuluh), Alih Bahasa Drs.Benyamin Molan.Jakarta : Salemba Empat.

Sagone, E., Maria E, dan De C. (2014). Locus of Control and Academic Self-Efficacy in University Students: The Effects of SelfConcepts. In 4th World Conference on Psychology, Counselling and Guidance, 114:222-28.

Sang, K. et. al. (2009). Anticipatory socialisation amongst architects: a qualitative examination. Education and Training, 51(4), 309-321.

Saputra, B. 2018. Pengaruh Retaliation dan Gender Terhadap Niat Melakukan Whistleblowing"Skripsi. Fakultas Ekonomi, Universitas Negeri Padang.

Sari, D.N., dan Laksito, H.(2014). Profesionalisme Internal Auditor Dan Intensi Melakukan Whistleblowing (Studi Empiris: Auditor Internal Perbankan Di Indonesia)." Diponegoro Journal of Accounting 3: 1-8. 
Sary, Desy, R., Amir, H. dan Elfi, I.(2015) Pengaruh Pengalaman Auditor, Komitmen Profesional, Tekanan Ketaatan dan Nilai Etika Organisasi terhadap Persepsi Pertimbangan Etis (Studi Empiris Pada Kantor BPKP - RI Perwakilan Provinsi Riau). Jom FEKON 2(2), $1-15$.

Sheehan, Norman T, dan Joseph A.S.(2015). Preparing Accounting Students for Ethical Decision Making : Developing Individual Codes of Conduct Based on Personal Values. Journal of Accounting Education 33 (3), 183-97.

Sugiyono. (2012). Statistika Untuk Penelitian Kuantitatif. Bandung : Alfabeta.

Sulistomo, A dan Prastiwi, A.(2012). Persepsi Mahasiswa Akuntansi terhadap Pengungkapan Kecurangan (Studi Empiris Mahasiswa Akuntansi UNDIP dan UGM). Eprints Undip: 128.

Taylor, E.Z dan Mary B.C. (2010). An Examination Of The Layers Workplace Influence In Ethical Judgement: Whistleblowing Likelihood and Perseverance in Public Accounting. Journal of Business Ethics, 93, 21-37.

UU No. 13 tahun 2006 tentang Perlindungan Saksi dan Korban, https://www.komisiinformasi.org/regulasi/

Wahid, B. (2014). Analisis komitmen profesional dan sosialisasi antisipatif serta hubungannya dengan Whistleblowing. Journal Al-Mizan, 10(1), 152-168.

Weight, (1977). An EmpiricalStudy Of The Profesional Socialization of Accounting Student. International journal of Accounting,13 13-19.

Yani, J.F. (2014). Pengaruh komitmen profesional dan sosialisasi antisipasif mahasiswa audit terhadap perilaku whistleblowing. Jurnal Bisnis Dan Manajemen, 4(2), 198-209.

Yeoh, P. (2014). Whistleblowing: motivations, corporate self-regulation, and the law. International Journal of Law and Management, 56 (6), 459 - 474.

Yulianto, R. Dan Dimas, A. (2015). Pengaruh Orientasi Etika, Komitmen Profesional, dan Sensitivitas Etis Terhadap Whistleblowing. Jurnal Universitas Negeri Yogyakarta 